\title{
O ENSINO DE GEOGRAFIA E O CINEMA ${ }^{1,2}$
}

Grupo PET-Geografia ${ }^{3}$

\section{Resumo}

Este trabalho discute a utilização de filmes como recurso didático em aulas de Geografia. $\mathrm{O}$ ciclo de filmes proposto foi idealizado com o objetivo de estabelecer uma conexão entre três temas principais: expropriação da terra, migração e favelização dos grandes centros urbanos. Os três filmes escolhidos foram exibidos para alunos do ensino médio e discutidos em oficinas com duração de 2 horas. A escolha dos filmes nos permitiu abordar temáticas paralelas, e não menos importantes, tais como economia, cultura, clima e paisagem. Diário de Motocicleta proporcionou a abordagem e a discussão sobre a diversidade cultural existente na América do Sul, permitindo analisar e espacializar o mosaico cultural existente, através da construção de um mapa da América Latina. Caminho das Nuvens possibilitou visualizar a realidade vivida por inúmeras famílias de retirantes nordestinos, além da reflexão sobre desapropriação e de terra e migração com a caracterização do mosaico cultural e paisagístico, das diferenças e similaridades das regiões brasileiras num mapa temático. Em Cidade de Deus, estudamos o processo de favelização. Finalizada a discussão, nos dividimos em três grupos onde realizamos um trabalho de campo com os alunos pelas proximidades da escola. A atividade consistia em identificar o processo de favelização com a realidade vivida e o registro fotográfico.

Palavras-chave: recurso didático, mapas, ensino de geografia, desigualdades sociais, paisagem.

\section{Introdução}

O Programa de Educação Tutorial - PET, vinculado ao Ministério da Educação, é formado por 12 alunos do Curso de Graduação em Geografia da Universidade Federal do Ria

\footnotetext{
${ }^{1}$ Modalidade: Espaço de diálogos e práticas. Tipo: Relato de experiência prática. Eixo 2

${ }^{2}$ Eventos: EEG PUC/RS, IV Semana Acadêmica Geografia, Fala Professor 2007, Salão de Extensão.

${ }^{3}$ Everton de Moraes Kozenieski, Fábio Guadagnin, Neudy Alexandro Demichei, Heitor Alexandre Brandão Jr., Matheus Heizenreder Schaf, Tiago Bassani Rech, Rodrigo Bennett, Ana Stumpf Mitchell, Judeci da Silva, Graziela Bohush, Tiago Oliveira Nicoloso, Rosa Maria Vieira Medeiros.
} 
Grande do Sul. Primeiramente, o objetivo deste projeto era o de auxiliar na formação dos graduandos em Geografia da UFRGS. Num segundo momento, surge a idéia de realizarmos atividades que aproximassem a Geografia da realidade do aluno de ensino fundamental e médio. Dessa forma, optamos por fazer do Cine PET o instrumento para a concretização deste objetivo.

Durante as disciplinas de estágio obrigatório no ensino fundamental e médio, buscamos, então, apoio institucional para a realização deste projeto. Após o estabelecimento de alguns contatos com escolas da rede pública de Porto Alegre, obtivemos a aprovação da proposta do Cine PET pela direção da Escola Estadual de Ensino Médio Inácio Montanha.

Ao longo dessa atividade, nos deparamos com situações que vieram ao encontro de nossa proposição, a de que os filmes se mostram um bom recurso para a aproximação dos dois mundos que se encontram na sala de aula: o mundo científico-acadêmico e o mundo cotidiano-juvenil.

Discutimos aqui, portanto, quais os benefícios deste tipo de prática a partir de nossa experiência apresentando uma proposta de ciclo de filmes que foi e pode ser trabalhado no ensino médio. Este artigo inclui ainda uma listagem de filmes onde são sugeridas temáticas possíveis de serem trabalhadas.

\section{Triangulação e significado}

Ser professor é encarar um desafio todos os dias, é “... inquietar a razão e desfazer os hábitos do conhecimento objetivo..." (BACHELARD, 1996). A tarefa, árdua e recompensadora, de despertar o interesse dos alunos pelos conteúdos trabalhados durante as aulas de Geografia é quase exclusiva do professor. Estimular o interesse e tornar próximos e compreensíveis os conhecimentos da geomorfologia do continente asiático até a industrialização da América do Norte não apenas é um grande desafio que exige preparação, mas também desenvoltura de igual tamanho. É interessante apontar algumas das posturas que grande parte dos professores adota diante deste desafio.

Alguns, no limite extremo inferior da preocupação com o interesse do aluno, adotam uma postura indiferente e acomodada. Neste caso, não é o professor que precisa tornar as aulas interessantes, palpáveis, significantes; são os alunos que precisam se esforçar para entender algo completamente alheio à sua realidade. Este tipo de professor é comum na rede pública de ensino, seja no ensino fundamental ou no médio. São professores que fazem uso de linguagem por vezes inacessível, repetem as mesmas técnicas em aulas com temas 
completamente distintos e para públicos também distintos. Estes, quase invariavelmente, associam a falibilidade do processo de aprendizagem na falta de interesse do aluno, como se esse devesse se interessar pelas aulas estanques de clima, vegetação ou população, amontoado ou separado em caixinhas sem propósito aparente.

Outros professores, no entanto, no limite extremo superior da preocupação com o interesse do aluno, se esforçam por demais na tentativa de chamar a atenção do mesmo tornando a necessidade de atratividade um fim e não um modo de ensinar. Estes são muito comuns em cursinhos pré-vestibular, onde muitas vezes, é mais importante o entretenimento do que a aprendizagem. Acontece que ao recorrer a diversos recursos que procuram despertar o interesse pela aula, muitas vezes a atenção fica presa na figura do professor, e não no tema que está sendo trabalhado. Funciona? Acreditamos que, à curto prazo, possa funcionar. Contar piadas e fazer encenações dramáticas pode, de fato, prender a atenção do aluno e mesmo auxiliar a decorar determinados conteúdos. Mas, cremos que à longo prazo esse sucesso não se repita.

Não estamos aqui condenando esse tipo de artifício, pelo contrário, este tipo de recurso pode e deve ser usado, contanto que bem dosado e com um propósito que busque mais que a exaltação momentânea. O que tentamos dizer é que, os extremos não são o melhor caminho. É importante e extremamente necessário que procuremos práticas alternativas e que chamem a atenção, que fujam da monotonia tradicional do quadro-negro. A busca do ideal, passa então pelo casamento da atividade alternativa com o os objetivos do conteúdo que se trabalha. Devemos sim apresentar formas alternativas de ensino, mas não soltas, alheias à discussão e à realidade da sala de aula. Este simples esquema ilustra bem nosso desafio cotidiano.

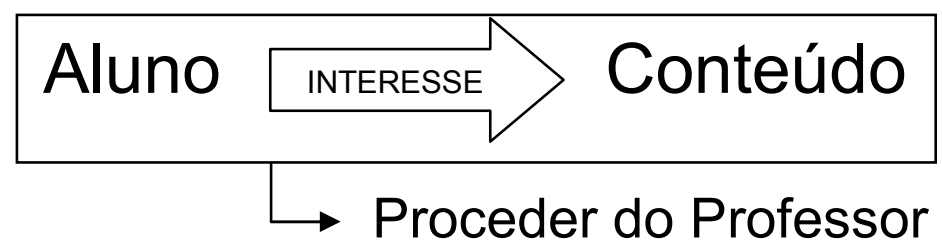

Nem sempre somos capazes de despertar o interesse dos alunos de maneira satisfatória. Os desafios são muitos: muitas turmas, muitos alunos, os temas são duros e diversos, o salário é baixo, etc. Muitas vezes pode passar desapercebida a responsabilidade que está por trás de fazer o conhecimento "científico" ter um significado prático, fazer este mundo estranho se aproximar, ou mesmo tangenciar o mundo no qual vivem os alunos. São inúmeros os artigos e livros que discutem e apontam alternativas para isto. Nossa intenção 
aqui é discutir uma alternativa que tem se mostrado frutífera durante nossas experiências em sala de aula: a utilização de filmes como recurso ilustrativo e reflexivo.

Um filme pode servir como um elemento de triangulação que facilite o contato entre o professor, os alunos e os objetivos traçados para os conteúdos, servindo como uma ponte de significado e auxiliando a aprendizagem. Este papel, em verdade, pode ser ocupado por inúmeros elementos e atividades lúdicas, tais como aquelas que fazem uso de imagens, músicas, jogos, poesia, passeios, etc. No entanto, é notório o efeito positivo da utilização de filmes; em primeiro lugar, pela familiaridade da linguagem cinematográfica, pois, a imensa maioria dos alunos de hoje foi criada diante de uma televisão. Assim, este tipo de atividade já sai em vantagem pois não conta com aquela resistência típica das tradicionais práticas de ensino.

Em segundo lugar, outra vantagem dos filmes é a facilidade de identificação dos alunos com a história e com as personagens. Inúmeros são os exemplos de filmes que relatam uma história do ponto de vista de um adolescente ou de uma criança. Outros pontos a serem explorados existem e serão discutidos adiante.

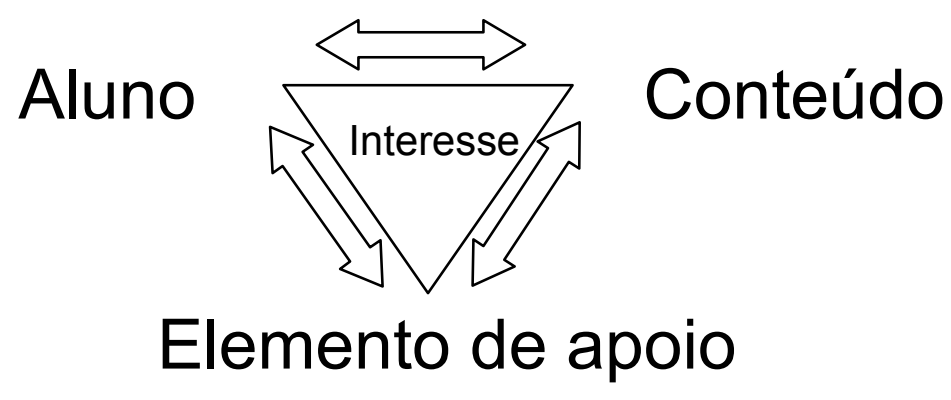

\section{Quanto à dimensão humana da Geografia}

A maioria dos livros didáticos de Geografia são ricos em dados, mapas e ilustrações. A maior falha que percebemos, no entanto, diz respeito à dimensão humana dos aspectos geográficos. Quando temos que trabalhar a distribuição climática no Brasil, por exemplo, apresentamos aos alunos inúmeras tabelas e mapas para demonstrar que o índice pluviométrico e a temperatura média da região nordeste do nosso país classificam as características daquela região como pertencentes a um clima semi-árido. Mas o que isto significa na prática? Em outras palavras, como isto afeta a vida de quem mora lá? Como vive quem mora lá? Estes aspectos da vida humana são tratados de maneira falha mais usualmente. Por vezes esta dimensão humana fica esquecida, como se fosse secundária. Precisamos 
lembrar que sem a sociedade não há clima, não há região, não há dados, não há temperatura, não há ensino, não há mundo. Todos estes conceitos são criações humanas. Se não há homem, não há nada, só espaço. E é aqui que muitos de nós caem na maior armadilha da Geografia: nós não devemos estudar o espaço em si mesmo, nós devemos sim é estudar a influência mútua entre sociedade e espaço e as razões de sua configuração. Sem homem, não há Geografia.

Acreditamos que o primordial não são as características do clima, da vegetação, da fauna, dos recursos hídricos, dos recursos minerais, da geomorfologia (a lista é longa), e sim, a influência disto tudo sobre a vida humana. E como todos estes elementos possuem uma espacialização própria e distinta, esta influência sobre a vida humana também será diferente em diferentes porções do espaço. O que nos leva de volta à nossa pergunta: como vive uma pessoa que habita uma região semi-árida? E nem precisamos ir tão longe: como vive uma pessoa que habita uma favela? Quantos de nossos alunos já entraram em uma? Dados estatísticos de violência e pobreza não comovem ninguém. A miséria humana e a degradação absoluta sim, têm o poder de criar indignação. Se quisermos mudar o mundo, é preciso começar mudando nossos alunos. E para mudar nossos alunos é preciso começar mudando nossas aulas. Ninguém se solidariza com dados estatísticos, nos solidarizamos com seres humanos, pessoas como nós, vivendo em condições sub-humanas.

Não temos que ter medo de mostrar a realidade a nossos alunos. Claro que nunca conseguiremos compreender por completo uma realidade sócio-espacial específica sem vivenciá-la. Mas sabemos bem que é muito difícil levarmos nossos alunos para fora dos limites da escola, imaginem então para fora dos limites da cidade ou do estado. Assim, a única alternativa que nos resta é trazer para dentro da sala de aula uma aproximação da realidade vivida. Algumas alternativas são possíveis, e acreditamos que uma das melhores seja a utilização de filmes. Através deles, podemos perceber alguns aspectos da vida cotidiana de pessoas em qualquer ponto do mundo.

Filmes que nos mostrem o mundo pelos olhos de suas personagens, que mostrem os conflitos e alegrias de outras realidades sócio-espaciais, que mostrem que o mundo não é só aquele que nossos olhos atingem. Uma possibilidade ainda melhor são os filmes narrados da perspectiva de adolescentes ou crianças, que criam uma empatia enorme entre os alunos e as situações que surgem na tela: “este poderia ser eu em outro lugar”. Esta situação possibilita uma percepção por parte do aluno daquilo que se aproxima e/ou destoa do seu mundo; 
permitindo também, visualizar que os aspectos geográficos são distintos, mas os sentimentos humanos diante destes são os mesmos, em quase todos os lugares do mundo.

\section{A escolha dos filmes: o imperativo da inteligibilidade}

A utilização de filmes já é uma prática relativamente difundida nas escolas públicas. A maior dificuldade talvez resida na escolha dos filmes: normalmente, são filmes didáticos e chatos, documentários ou filmes tão densos e intransponíveis que pouco dizem aos alunos. É por isso que a escolha dos filmes deve ser pautada pelo imperativo da inteligibilidade. Muitas vezes, com a (boa) intenção de diversificarmos as práticas em sala de aula, escolhemos filmes com um enorme potencial de discussão e que nos dizem muito. Porém, boa parte destes filmes acaba não tendo o efeito esperado porque não possui uma linguagem ou um contexto adequados ao público. Se priorizarmos o entendimento, a escolha de um filme que não nos diz tanto pode ser uma boa alternativa. Isto porque, embora suas reflexões sejam menos profundas, sua inteligibilidade é mais ampla, ou seja, embora nos diga menos, quase tudo pode ser compreendido pelo aluno. Precisamos nos perguntar se há nele elementos com os quais os alunos poderão se identificar e criar vínculos entre a sua realidade e o tema em discussão.

\section{O que os filmes têm a nos dizer: a Geografia dos filmes e o olhar geográfico}

Na escolha dos filmes, o importante é nos darmos conta que sempre há algo por trás da história romanceada que nos salta aos olhos. Há um primeiro plano de ação, mas também há um segundo plano que justifica, que influencia e é influenciado pelas ações que se passam neste primeiro plano. Não é fácil achar um filme que mostre explicitamente ações que possam ser interpretadas e diretamente conectadas aos temas em discussão em sala de aula. Por outro lado, não são poucos os filmes que usam um pano de fundo extremamente geográfico para contextualização da história. Um bom critério é nos perguntarmos: as ações apresentadas no filme poderiam estar ocorrendo em qualquer outro momento histórico ou em outra porção do espaço? Se a resposta for negativa, então o espaço constitui um importante elemento no desenrolar da história que está sendo contada. As ações humanas quase nunca estão descoladas do espaço e alheias ao seu entorno, portanto, quase tudo permite uma interpretação espacial. 
Não há quase nada de geográfico em um monte de explosões e cenas de ação típicas de um filme de agentes secretos, por exemplo, James Bond, em um de seus filmes recentes, precisa parar um terrorista que seqüestrou um submarino nuclear russo e ameaça explodi-lo próximo à cidade turca de Istambul. Bom, vejamos: mais um filme de ação como qualquer outro que atrai imensamente adolescentes como aqueles que habitam nossas salas de aula. As ações em primeiro plano podem não ser essencialmente geográficas, mas o pano de fundo em que elas se apóiam é. Por que será que há um terrorista no filme? O que é terrorismo? Porque foi seqüestrado um submarino russo e não um de outro país? Será porque aquele país saiu derrotado da Guerra Fria e hoje não consegue controlar o imenso arsenal de guerra que lhe sobrou como herança? Por que será que o terrorista quer explodir Istambul? Por que será que um agente secreto britânico estaria defendendo a Turquia?

As repostas para estas perguntas fazem parte de uma estrutura espacial que não é de todo fictícia e que passa despercebida aos olhares desatentos. Todas estas perguntas são Geografia pura. Este é um excelente exemplo de como filmes aparentemente vazios podem ser explorados. A grande vantagem em se fazer isso é poder utilizar filmes que de fato sejam atraentes para os alunos. Fugimos dos tradicionais filmes e documentários maçantes e ainda assim temos um excelente campo de discussão em Geografia.

Assim, foram escolhidos filmes bastante diversos e de grande apelo popular. Com isto, queremos dizer que o grande objetivo por trás do ciclo de filmes que propomos foi mostrar que há Geografia em quase tudo, procurando desenvolver o olhar para que esta Geografia quase invisível possa ser vista, trazendo-a ao plano principal e debatendo-a.

\section{Filmes e atividades}

O Ciclo de Filmes foi idealizado com o objetivo de estabelecer uma conexão entre três temas principais: expropriação da terra, migração e favelização dos grandes centros urbanos. A partir de uma pesquisa minuciosa, entre tantas possibilidades de filmes a serem utilizados, chegamos aos seguintes títulos - Diários de Motocicleta, O Caminho das Nuvens e Cidades de Deus.

Os três filmes escolhidos foram exibidos para alunos do ensino médio e discutidos em oficinas com duração de 2 horas. Apresentamos também as atividades propostas depois de cada um dos filmes e os seus resultados. A ordem dos filmes foi definida de acordo com o grau de facilidade para identificação dos elementos geográficos em cada filme. Assim, o 
primeiro deles apresentava elementos bastante explícitos, enquanto o último exigia maior refinamento para percepção dos elementos. Desta forma, acreditamos que, além de avaliar o sucesso das atividades propostas para cada filme, foi também possível avaliar a evolução da turma diante do aumento de exigência ao longo do ciclo de filmes.

\section{Diários de Motocicleta:}

Site Oficial: www.motorcyclediaries.net

Direção: Walter Salles

Roteiro: Jose Rivera, baseado nos livros de Che Guevara e Alberto Granado

O que foi trabalhado a partir do filme: Este filme nos proporcionou uma abordagem e discussão sobre a diversidade cultural existente na América do Sul, permitindo analisar e espacializar o mosaico cultural existente, despertando no aluno o interesse de descobrir, de desvendar as riquezas existentes nos países vizinhos ao Brasil. Discutimos também o processo histórico de dominação e exploração sofrida pelos povos sul americanos além da expropriação da terra como conseqüência desse processo. Paralelamente, foi possível trabalhar os elementos relacionados à paisagem da América do Sul, além de aspectos culturais, uma vez que as personagem principais da trama percorrem um longo trajeto entre a Patagônia Argentina, a Região Andina e a Amazônia venezuelana.

Atividade proposta: Primeiramente, iniciamos a atividade apresentando um mapa ilustrativo da América do $\mathrm{Sul}^{4}$, representando o caminho percorrido por Che Guevara e seu companheiro Alberto Granada no filme "Diários de Motocicletas".

Propomos, então, a divisão desse percurso em quatro trechos, ficando responsável por cada trecho um grupo de alunos, a saber:

Grupo 1: Trecho de Córdoba (Argentina) até Bariloche (Argentina).

Grupo 2: Trecho de Bariloche (Argentina) até Lima (Peru).

Grupo 3: Trecho de Lima (Peru) até San Pablo (Peru).

Grupo 4: Trecho de San Pablo (Peru) até Caracas (Venezuela).

Com o apoio de revistas, cada grupo teve de coletar gravuras para ilustrar e confeccionar o mapa temático. Posterior ao termino da elaboração do mapa, realizamos uma discussão sobre aspectos culturais e paisagísticos dos trechos, distribuindo no mapa em papel pardo a diversidade etnográfica e paisagística da América do Sul. Nesse momento, foi realizado um debate sobre o processo histórico de ocupação do território sul americano

\footnotetext{
${ }^{4}$ Este material foi confeccionado, previamente, a partir da projeção de uma lâmina do mapa da América do Sul sobre um papel pardo $(1,5 \mathrm{~m}$ x 2,5m) fixado em uma parede. Estas dimensões foram fundamentais para melhor desenvolvermos esta atividade.
} 
ressaltando os impactos decorrentes da dominação e exploração sofrida pelos povos, bem como a conseqüente expropriação da terra. Ao longo da exibição do filme, foi possível verificar algumas manifestações por parte dos alunos no sentido de identificarem na trama elementos anteriormente trabalhados em sala de aula.

Material utilizado:

- Fita VHS do filme Diários de Motocicleta, Livro Diários de Motocicleta, CD com a trilha original do filme, Mapa da América do Sul em papel pardo, Revistas ${ }^{5}$, tesouras, cola, pincéis atômicos e fita adesiva.

\section{$\underline{\text { O Caminho das Nuvens }}$}

Site Oficial: www.ocaminhodasnuvens.com.br

Direção: Vicente Amorim

Roteiro: David França Mendes

O que foi trabalhado a partir do filme: Este filme possibilita visualizar a realidade vivida por inúmeras famílias de retirantes nordestinos que deixam sua terra natal em busca de melhores oportunidades nos grandes centros urbanos. Com isso, estabelecemos uma conexão entre o problema da expropriação da terra, apresentado no primeiro filme, e sua maior conseqüência - o processo de migração. As atividades trabalhadas no segundo dia pouco se diferenciaram das do dia anterior. Os assuntos abordados, tais como expropriação de terras, migração, paisagens naturais e diferenças etnográficas diferiram das do dia anterior quanto à escala, pois este constitui-se numa escala nacional, local.

Atividade proposta: Sendo o Brasil um país de grandes extensões, os espaços vividos apresentados no filme diferenciavam-se em alguns aspectos da realidade vivida pelos alunos, principalmente quando abordada a questão paisagística e cultural. Para tanto, propomos a divisão da turma em cinco grupos, cada um representando uma das cinco regiões brasileiras.

Neste dia, a metodologia empregada diferiu-se do dia anterior. Primeiramente exibimos o filme, buscando estabelecer uma conexão entre os temas anteriormente abordados e as diferenças regionais existentes no Brasil. Exibido o filme, iniciamos a construção de um mapa temático cuja base era a divisão regional do Brasil. Em um primeiro momento, cada grupo ficou responsável por escolher figuras relacionadas com a sua região, mencionando características presentes nas figuras e associadas à mesma.

\footnotetext{
5 As revistas foram selecionadas conforme a temática desejada e adquiridas em sebos a preços bastante reduzidos.
} 
Posteriormente, foi desenvolvida uma atividade cujo elemento de apoio foi a música. Para tanto, foram entregues as letras de cinco canções representativas de cada região. Cada uma delas foi ouvida na intenção de extrair das mesmas palavras e ritmos representativos de cada região brasileira. Após a caracterização das músicas, realizamos uma discussão sobre cada aspecto apontado pelos alunos. Finalizada esta discussão, inserimos no mapa as características apontadas por eles onde, juntamente com as figuras já inseridas, foi possível elaborar um mapa temático caracterizando o mosaico cultural e paisagístico bem como as diferenças e similaridades do nosso país.

Material utilizado:

- Fita VHS do filme O Caminho das Nuvens, Mapa do Brasil em papel pardo, Revistas, tesouras, cola, pincéis atômicos e fita adesiva;

- Músicas:

Música 1: Região Norte; Banda Calypso - Brega Fo

Música 2: Região Nordeste; Chico Science, A Cidade

Música 3: Região Centro Oeste; Tião Carreiro e Pardinho, Travessia do Araguaia

Música 4: Região Sudeste; O Rappa, O que Sobrou do Céu

Música 5: Região Sul; Neto Fagundes, Origens

\section{Cidade de Deus}

Site Oficial: www.cidadededeus.com.br

Hot Site: www.adorocinemabrasileiro.com.br

Direção: Fernando Meirelles

Roteiro: Bráulio Mantovani, baseado em romance de Paulo Lins

O que foi trabalhado a partir do filme: Com o filme Cidade de Deus concluímos o ciclo de atividades, trabalhando o processo de migração e a conseqüente favelização dos grandes centros urbanos. A esperança de uma nova vida, a luta pela sobrevivência e as alternativas encontradas por esses migrantes estiveram no centro dos debates deste terceiro e último dia.

Atividade proposta: Após uma breve conversa onde foi feita uma retrospectiva dos encontros anteriores, teve início a exibição do filme Cidade de Deus. A estrutura desta atividade foi dividida em dois momentos. Primeiramente exibimos o filme, com a finalidade de provocar a construção de uma visão crítica dos alunos frente ao processo de desigualdade socioeconômico existente em nosso país (favelas x arranha-céus), problematizando o processo 
de expropriação visualizado nos filmes anteriores, a decorrente migração para os grandes centros urbanos e a segregação urbana.

O segundo momento esteve estruturado através de uma atividade lúdica (saída de campo), onde dividimos a turma em três grupos, ficando cada grupo responsável pela coleta de imagens, através de fotografias tiradas das áreas visitadas. Esta atividade foi proposta no sentido de aproximar os alunos da realidade vivida pelo personagem principal da trama. Nesta, Buscapé é um adolescente que encontra na fotografia uma forma de expor os dramas cotidianos de sua comunidade e de se encontrar como sujeito ativo de transformação desta realidade. Dessa forma, cada grupo recebeu uma máquina fotográfica e dois filmes de 12 poses cada. Os alunos, nessa ocasião, puderam registrar as situações presenciadas e que lhes remetiam a tudo o que havíamos trabalhado até o momento.Três foram os locais escolhidos para esta atividade que, de um modo geral, representavam estruturas socioeconômicas diferenciadas:

Grupo 1: Parque Farroupilha (Redenção).

Domínio público, onde é possível visualizar a circulação de pessoas de diferentes classes sociais

Grupo 2: Vila Planetário.

Conjunto habitacional localizado junto a Av. Ipiranga, constituída por população de baixa renda.

Grupo 3: Azenha e Menino Deus.

Bairros que representam a interface de duas realidades socioeconômicas diferentes.

Material utilizado:

- Fita VHS do filme Cidade de Deus, Máquinas fotográficas

\section{Outras sugestões: mais filmes que podem nos ajudar}

A seguir, relacionamos mais alguns filmes que podem ser utilizados nas aulas de Geografia e os temas abordados por cada um. Boa parte deles não trabalha exclusivamente um tema específico, em função disto, sugerimos que sejam vistos de forma ampla para que os vários aspectos possam ser explorados ao mesmo tempo.

\begin{tabular}{|l|l|}
\hline Filme & \multicolumn{1}{c|}{ Principais temas abordados } \\
\hline A Era do Gelo & Deriva continental, placas tectônicas e migração. \\
\hline
\end{tabular}




\begin{tabular}{|l|l|}
\hline A Máquina do Tempo & Evolução do relevo e organização social. \\
\hline A Sombra e a Escuridão & Colonização do continente africano. \\
\hline Abril Despedaçado & A condição humana no sertão nordestino. \\
\hline Amistad & Colonialismo e tráfico de escravos. \\
\hline Caramuru, A invenção do Brasil & Grandes Navegações e Mercantilismo. \\
\hline Central do Brasil & A realidade sócio-espacial brasileira. \\
\hline Crazy People - Muito Doidos & Mercado e estratégias de marketing. \\
\hline Duelo de Titãs & Superação do preconceito racial. \\
\hline Fábrica de Loucuras & O processo industrial: Fordismo vs Toyotismo. \\
\hline Fahrenheit 9/11 & Conflitos mundiais no início do século XXI. \\
\hline Highlander & Aquecimento global e camada de ozônio. \\
\hline Independence Day & Igualdade entre os povos e relações internacionais. \\
\hline Mad Max & Questões ambientais e escassez de água. \\
\hline O Grande Ditador & Segunda Guerra Mundial. \\
\hline O Terminal & Relações internacionais e domínio norte-americano. \\
\hline O Último Imperador & A Revolução Cultural chinesa. \\
\hline Tempo de Glória & Preconceito racial e luta pelo fim do racismo. \\
\hline Tempos Modernos & Capitalismo industrial e fordismo. \\
\hline Tiros em Columbine & Mídia, poder e controle social. \\
\hline Todos os Homens do Presidente & O escândalo de Watergate. \\
\hline Trocando as bolas & Capitalismo financeiro e bolsa de valores. \\
\hline Uma mente brilhante & A Guerra Fria e a guerra de informações. \\
\hline Volcano & Placas tectônicas e vulcanismo. \\
\hline WaterWorld & Questões ambientais e aquecimento global. \\
\hline
\end{tabular}

\section{Considerações}

Passado o primeiro ciclo do CinePet algumas considerações podem ser feitas, não apenas sobre o desenvolvimento da atividade em si, como também de seu papel, como facilitador do trabalho do professor, no caso, da prática docente em geografia. Em primeiro lugar, pudemos comprovar o questionamento inicial, sobre o real do potencial do trabalho com filmes. Estes, se mostraram importante instrumento de ensino e interessante elemento de apoio no trabalho com alunos. Parte desta realidade é explicada pelo fato de que a linguagem 
cinematográfica nos é, de modo geral, cotidiana. Tal fato desperta em crianças e adolescentes, nos alunos de forma geral, uma identificação com filmes, uma vez que estes retratam acontecimentos que por vezes copiam a realidade ou materializam o desconhecido, aquelas regiões longínquas, difíceis de serem vivenciadas. (Talvez caiba uma citação ou comentário do pequeno príncipe)

Na prática, sabemos que existe uma dificuldade na relação aluno/sala de aula, pois, estes estão diferentemente estruturados. Enquanto o aluno é informal; desempenhando aquelas características comuns à convivialidade, ao diálogo, à brincadeira; a sala de aula é formal, limitando o diálogo, o espaço do corpo, o tempo, indicando outra lógica pré-estabelecida de convivência. Foi neste contexto que a inserção de atividades lúdicas, no nosso caso, filmes; proporcionou uma proximidade entre aluno e sala de aula, tornando o espaço da sala de aula um momento prazeroso.

Logo, se a aula se torna mais prazerosa e atrativa, o resultado do que é trabalhado torna-se também mais significativo, pois, o aluno irá inserir-se melhor na atividade. Cabe lembrar que no trabalho com filmes; mesmo este propiciando a aproximação/identificação do aluno com as personagens, com o que se passa no enredo, torna-se determinante o papel do professor, explorando itens relacionados ao tema proposto, trazendo o filme para "dentro" do conteúdo a ser trabalhado. Cremos deste modo que facilitamos à construção do olhar geográfico do aluno.

Baseados em nossas atividades, podemos afirmar com certeza que o filme é um instrumento facilitador na relação professor/aluno, e no apoio para a constituição das aulas. Quanto à construção do olhar geográfico, a impressão deixada pelos alunos é de que, o trabalho em sala de aula a partir do cinema ao aproximar a realidade informal do aluno à realidade formal da sala de aula, tanto auxilia a prática pedagógica do professor, quanto facilita na construção deste olhar. Mostrando-se assim uma atividade na qual se confia uma formação mais interessada e duradoura, um vez que o resultado do trabalhado em sala de aula não vem à curto prazo.

\section{Referências bibliográficas}

ARALDI, A R. Construção do conhecimento através da interdisciplinaridade. In: REGO, N; SUERTEGARAY, D; HEINDRICH, A. Geografia e Educação: geração de ambiências. Porto Alegre: Editora da Universidade/UFRGS, 2000;

BARBOSA, J L. A Arte de Representar como o Reconhecimento do Mundo: o Espaço Geográfico, o Cinema e o Imaginário Social. In Revista Geografia. Niterói: UFF, 2000; 
BACHELARD, G. A formação do espírito científico: contribuição para uma psicanálise do conhecimento - Rio de Janeiro: Contraponto, 1996;

CALLAI, H C. A Geografia e a escola: muda a geografia? Muda o ensino? Revista Terra Livre, São Paulo, n. 16 - $1^{\circ}$ sem/2001. p. 134-151;

CARRANCHO, A. Todo o professor precisa ser um pouco "Leila Diniz". Rio de Janeiro: Unisinos. Disponível em:

www.humanas.unisinos.br/ambiente/oficinas/upload/tap/saber.doc. em 24/10/2004;

CASTROGIOVANNI, A C (org). Geografia em sala de aula - práticas e reflexões. Porto Alegre: Editora da Universidade, 1999 (2 ed);

FROMM, E. A Revolução da Esperança: Por uma Tecnologia Humanizada. Rio de Janeiro: Zahar Editores, 1975. 2 ed;

GEIGER, P P. Ciência, arte e Geografia no cinema de David Lynch. In GEOUSP. Espaço e Tempo. São Paulo, n 15, 2004;

LARROSA, J B. Notas sobre a experiência e o saber de experiência. Revista Brasileira de Educação, São Paulo, n. 19, p. 20-28, jan./abr. 2002;

MACHADO, N J. Cidadania e Educação. São Paulo: Escrituras Editora, 1997

REGO, N; REFFATTI, L V. Geografias Adversas e Manejo Simbólico. In: AGB - Seção Porto Alegre. Boletim Gaúcho de Geografia. Porto Alegre: EDIUPF. n. 29, jan./jun. 2003;

REGO, N; SUERTEGARAY, D; HEINDRICH, A. Geografia e Educação: geração de ambiências. Porto Alegre: Editora da Universidade/UFRGS, 2000; 